\title{
Optimal operation and marginal costs in simple trigeneration systems including thermal energy storage
}

\author{
Eduardo A. Pina, Miguel A. Lozano, Luis M. Serra \\ GITSE - Aragon Institute of Engineering Research (I3A), Department of Mechanical Engineering, \\ Universidad de Zaragoza, Calle María de Luna 3, 50018, Zaragoza, Spain
}

\begin{abstract}
The development of high-efficiency energy systems is a pressing issue nowadays, motivated by economic, environmental, and social aspects. Trigeneration systems allow for the rational use of energy by means of appropriate energy integration and provide greater operational flexibility, which is particularly interesting for buildings, often characterized by variable electricity, heating, and cooling demands. The benefits of trigeneration systems can be enhanced by the incorporation of thermal energy storage (TES), which decouples production and consumption. This paper analyses the operation of a simple trigeneration system including TES. The optimal operation is obtained by a linear programming model that minimizes the total variable cost. A thermoeconomic analysis based on marginal cost assessment of the internal flows and final products of the system is carried out, allowing to explain the optimal operation of the system and the role of the TES in achieving the optimal solution. The analysis unravels the marginal cost formation process, presenting a clear route from the final products obtained to the resources consumed. This information can aid the design of new plants, the retrofit of existing ones, and the operational management to achieve the minimum operational cost.
\end{abstract}

Keywords: marginal costs, operational strategy, thermal storage, thermoeconomics, trigeneration.

\section{Introduction}

Sustainability-related issues, such as the efficient use of energy, the depletion of fossil fuels resources, and the increase in greenhouse gas emissions, have become ever-present themes in the design of energy systems over the years. Energy process integration not only leads to higher energy efficiency, but also reduces environmental burdens and the economic cost of the final products $[1,2]$.

The combined production of two or more energy products from the same resource, as a result of appropriate energy integration, is a defining characteristic of polygeneration systems. Cogeneration, or Combined Heat and Power (CHP), has been successfully applied in the industrial sector for decades. The building sector accounts for $40 \%$ of the total energy use in the European Union [3]. By combining cogeneration with thermally activated technologies, such as absorption chillers, the thermal coverage can be extended to meet refrigeration demands. There is a large potential for trigeneration systems (or Combined Cooling, Heat, and Power - CCHP) in the building sector, for example of countries in the Mediterranean area. In fact, the European Commission's Energy Performance of Buildings Directive [3] recognizes cogeneration as a strategic technology to contribute towards reducing energy dependency.

In the design of trigeneration systems for buildings, two fundamental issues must be addressed [4]-[6]: (i) the synthesis of the plant configuration (installed technologies and capacities); and (ii) the operational planning (strategy concerning the operational state of the devices, energy flow rates, purchase/selling of electricity, etc.). For existing plants, the only concern is the operational planning; however, in the case of new plants, the design procedure is more complex because of the wide variety of commercially available technologies, the variability of energy demands (hourly and monthly), and the fluctuations in energy prices [7,8]. A common approach to this problem is the single objective model aimed at identifying the minimum cost as the objective function. The reviews of $[9,10]$ gather the characteristics of the optimization methods for polygeneration systems presented in recent publications, indicating the time scale, the objective function, and the solution method employed.

Thermal energy storage (TES) is playing an increasingly important role in the design of polygeneration systems, as demonstrated by several works [11]-[15]. As discussed in [16,17], the incorporation of TES is 
particularly interesting for systems with: (i) time-varying electricity prices; (ii) low-grade waste heat production; and (iii) non-manageable renewable energy sources (RES). As a result, TES ensures energy security and environmental quality, reduces operation costs, and enhances overall system performance. Furthermore, it allows to reduce installed capacity of equipment, and thus capital costs.

The fundamental problem of cost allocation can be formulated as follows [18]: Given a system whose limits have been defined and a level of aggregation that specifies the constituting subsystems, how to obtain the cost of all flows becoming interrelated in such structure. This task is further complicated as energy systems become more complex: multiple fuels (each with their prices), multiple products, multiple technologies, the incorporation of TES, and the energy integration (in a way that a change in the production of a flow may affect others, e.g. production of electricity and recovered heat in a cogeneration module).

The thermoeconomic analysis of the optimal solution explains the reasons for the operational mode, obtains the marginal costs of internal flows and final products, and evaluates the economic impacts of changes in the demands or in the operational conditions of the devices [19].

The marginal cost corresponds to the cost of producing one more unit of a product. Therefore, it offers a clear route to understanding and managing the behavior of costs throughout the system. Because marginal costs are directly related to production, marginal cost assessment can [20]: (i) motivate investments in infrastructure and equipment, improving efficiency and reducing operational costs; (ii) present variation of production costs; and (iii) reflect variations in the market prices of the resources. Marginal costs have been used to provide information about the operation of energy systems in the building sector [19], waste facilities [21], power plants (site model) [22], site utility systems focusing on steam production [23], and district heating facilities [20,24], to name a few examples. Quelhas et al. [25] used marginal costs to analyze the influence of the various fuel networks (production, transportation and delivery of fossil fuels to the power plants) on the electric network.

In a previous paper, Lozano et al. [19] have demonstrated the utility of assessing the marginal costs of the internal flows and final products of a simple trigeneration system. The incorporation of TES adds a new dimension to the cost allocation problem, as it requires determining not only the device that is producing the flow, but also the time in which the production took place. Therefore, taking the work developed by Lozano et al. [19] as starting point, the present paper aims to contribute by incorporating TES in the simple trigeneration system, determining its optimal operation for a day of the year by means of a linear programming (LP) model, and using the marginal costs obtained by the model to explain the optimal operation of the system and the role of the TES in achieving the optimal solution. It must be noted that the purpose of this study is to demonstrate the methodology and the power of marginal cost analysis. As stated in the title of the paper, the trigeneration system and the example developed herein are simple, but they allow for interesting analyses and conceptual interpretations.

\section{Simple trigeneration system including thermal energy storage}

Trigeneration systems are distinguished by the numerous alternative devices incorporated and existing configuration modes [7]. Basically, a trigeneration system is composed of a cogeneration module and a thermally activated technology. The cogeneration module consists of a prime mover (e.g. reciprocating internal combustion engine, gas turbine), which converts the chemical energy of the fuel into shaft power, an electricity generator, and heat recovery system. Thermally activated technologies (e.g. absorption chillers, adsorption chillers, desiccant dehumidifiers) are responsible for providing cooling and must be chosen to couple with the prime mover [8]. Auxiliary devices commonly incorporated in trigeneration systems are boilers and electric chillers.

The simple trigeneration system analyzed herein, presented in Fig. 1, consists of a cogeneration module $\mathrm{CM}$, consuming natural gas $F_{c}$ and producing cogenerated electricity $W_{c}$ and heat $Q_{c}$, an auxiliary boiler $\mathrm{AB}$, consuming fuel-oil $F_{a}$ and producing heat $Q_{a}$, an absorption chiller AC that provides cooling $R_{q}$, an electric chiller EC that provides cooling $R_{e}$, and a thermal energy storage TES, used to store chilled water. The TES can be either charging $R_{\text {in }}$ or discharging $R_{\text {out }}$; energy losses $R_{s}$ are proportional to the stored 
energy $S_{r}$ and to the TES energy loss factor $\tau_{T E S}$. It was considered that the devices can operate at partial load without affecting their performances. Table 1 presents the technical parameters and capacity limits of the system's devices.

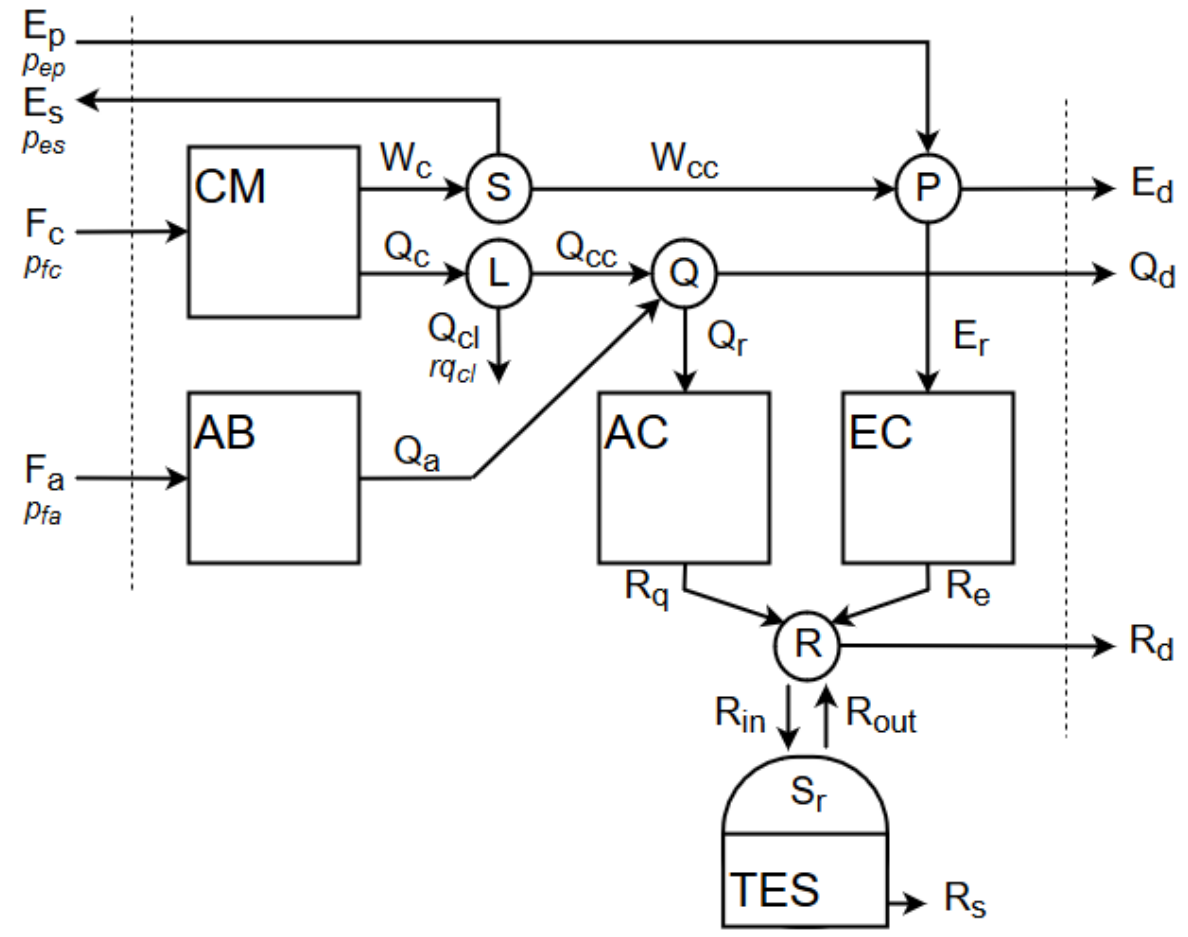

Fig. 1: Diagram of the simple trigeneration system analyzed.

Table 1: Technical parameters and capacity limits of the trigeneration system's devices

\begin{tabular}{|c|c|c|}
\hline Device & Technical parameters & Capacity limits \\
\hline Cogeneration Module (CM) & $\begin{array}{c}\alpha_{w}=W_{c} / F_{c}=0.35 \\
\alpha_{q}=Q_{c} / F_{c}=0.40\end{array}$ & $W_{\max }=350 \mathrm{~kW}$ \\
\hline Auxiliary Boiler (AB) & $\eta_{q}=Q_{a} / F_{a}=0.80$ & $Q_{\max }=400 \mathrm{~kW}$ \\
\hline Absorption Chiller (AC) & $C O P_{q}=0.625$ & $R_{q, \max }=250 \mathrm{~kW}$ \\
\hline Electric Chiller (EC) & $C O P_{e}=5$ & $R_{e, \max }=250 \mathrm{~kW}$ \\
\hline Thermal Energy Storage (TES) & $\tau_{T E S}=0.01 \mathrm{~h}^{-1}$ & $V_{\max }=2000 \mathrm{kWh}$ \\
\hline
\end{tabular}

The trigeneration system was designed to attend the electricity $E_{d}$, heating $Q_{d}$, and cooling $R_{d}$ demands of a consumer center (e.g. multifamily building). The energy demands are described by 24 consecutive periods of 1-hour duration, as presented in Table 2.

Natural gas and fuel-oil are purchased at prices $p_{f c}=0.025 € / \mathrm{kWh}$ and $p_{f a}=0.020 € / \mathrm{kWh}$, respectively. Electricity can be purchased from the grid $E_{p}$ at price $p_{e p}=0.100 € / \mathrm{kWh}$ and sold $E_{s}$ at a price $p_{e s}=0.080$ $€ / \mathrm{kWh}$. There is the possibility of wasting cogenerated heat into the environment $Q_{c l}$ and it was considered that no cost was associated with such dissipation $r q_{c l}=0 € / \mathrm{kWh}$.

Finally, the reasons for including a TES for cooling and not for heat (or both) were that (i) the cooling demand presents higher variations throughout the day compared to the heating demand, and (ii) the aim of this paper is to demonstrate the methodology and the power of marginal cost analysis; including two or more TES devices would hinder the clarity of the analysis. 


\section{Mathematical model}

In a trigeneration system as the one analyzed herein, each energy service can be provided by more than one device. For example, heating can be produced by the $\mathrm{CM}$ consuming natural gas or by the $\mathrm{AB}$ consuming fuel-oil. Given the multiple devices of the system, their capacity and performance, the fuel and electricity prices, and the energy demanded by the consumer center, several operation strategies are possible. The optimal operational planning of the plant that minimizes or maximizes a given objective function can be determined by a LP optimization model.

The LP optimization model developed in the present work minimizes the daily operation cost $D C$, which corresponds to the sum of the hourly operation cost $H C(h)$ for the 24 periods $h(N P=24)$ of 1-hour duration $(N H P=1)$ that comprise the day:

$$
\operatorname{Min} D C=\sum_{h=1}^{N P} H C(h)
$$

For each hourly period $h, H C(h)$ includes the costs of purchasing electricity, natural gas, and fuel-oil, the cost associated with heat dissipation, and the income from selling electricity to the grid, as expressed by Eq. (2).

$$
\begin{aligned}
H C(h)=N H P & \cdot\left(p_{e p}(h) \cdot E_{p}(h)+p_{f c}(h) \cdot F_{c}(h)+p_{f a}(h) \cdot F_{a}(h)+r q_{c l}(h) \cdot Q_{c l}(h)\right. \\
& \left.-p_{e s}(h) \cdot E_{s}(h)\right)
\end{aligned}
$$

The objective function is subject to equipment constraints (capacity limits and production restrictions) and balance equations.

\section{Equipment constraints}

For each hourly period $h$, the productions of the devices are limited to their capacity limits, as expressed by Eqs. (3)-(6). In the case of the TES, the energy stored at the end of each period $S r_{f}(h)$ is limited to the maximum storage capacity $V_{\max }$, according to Eq. (7).

$$
\begin{array}{ll}
\text { CM_Wmax: } & W_{c}(h) \leq W_{\max } \\
\text { AB_Qmax: } & Q_{a}(h) \leq Q_{\max } \\
\text { AC_Rqmax: } & R_{q}(h) \leq R_{q, \max } \\
\text { EC_Remax: } & R_{e}(h) \leq R_{e, \max } \\
\text { Srf_Vol: } & S r_{f}(h) \leq V_{\max }
\end{array}
$$

Eqs. (8)-(12) express the equipment efficiency restrictions:

$$
\begin{array}{ll}
\text { CM_W: } & \alpha_{w} \cdot F_{c}(h)-W_{c}(h)=0 \\
\text { CM_Q: } & \alpha_{q} \cdot F_{c}(h)-Q_{c}(h)=0 \\
\text { AB_Q: } & \eta_{q} \cdot F_{a}(h)-Q_{a}(h)=0 \\
\text { AC_R: } & \operatorname{COP}_{q} \cdot Q_{r}(h)-R_{q}(h)=0 \\
\text { EC_R: } & \operatorname{COP}_{e} \cdot E_{r}(h)-R_{e}(h)=0
\end{array}
$$

The energy losses $R_{s}(h)$ are equal to the energy stored at the end of the previous period $S_{r f}(h-1)$ multiplied by the TES energy loss factor $\tau_{T E S}$ :

$$
R_{S}(h)=\tau_{T E S} \cdot S_{r f}(h-1)
$$

Given the daily regularity of the energy demands, the TES was considered to return to its initial state, which means that the energy stored at end of the day $S_{r f}(24)$ must be the same as the energy stored at the beginning 
of the day $S_{r i}(1)$ (Eq. (14)). Because of the continuous operation of the TES, it follows that the energy stored at the beginning of an hourly period $S_{r i}(h)$ must be the same as the energy stored at the end of the previous period $S_{r f}(h-1)$ (Eq. (15)).

$$
\begin{aligned}
& S_{r i}(1)=S_{r f}(24) \\
& S_{r i}(h)=S_{r f}(h-1)
\end{aligned}
$$

\section{Balance equations}

The energy balances in the junctions and distributors of the system are expressed by Eqs. (16)-(20).

$$
\begin{array}{ll}
\text { S: } & W_{c}(h)-E_{s}(h)-W_{c c}(h)=0 \\
\text { P: } & W_{c c}(h)+E_{p}(h)-E_{r}(h)-E_{d}(h)=0 \\
\text { L: } & Q_{c}(h)-Q_{c c}(h)-Q_{c l}(h)=0 \\
\text { Q: } & Q_{a}(h)+Q_{c c}(h)-Q_{r}(h)-Q_{d}(h)=0 \\
\text { R: } & R_{q}(h)+R_{e}(h)+R_{\text {out }}(h)-R_{\text {in }}(h)-R_{d}(h)=0
\end{array}
$$

Energy balance in the TES yields the following expression:

$$
\text { TS: } \quad S_{r i}(h) / N H P+R_{\text {in }}(h)-R_{\text {out }}(h)-R_{s}(h)-S_{r f}(h) / N H P=0
$$

It should be noted that the model could be more complex by considering more detailed operation conditions (e.g. minimum capacity limits of the devices, cost of heat dissipation, performance variations with load, time changing electricity tariffs). However, in accordance with [19], increasing the complexity of the model would not provide more relevant conclusions and would hide, to some extent, the clarity of the analysis. Furthermore, this evaluation only considers the operational costs of the system; however, capital costs could be easily incorporated in the analysis

\section{Optimal operation}

Given the technical parameters and capacity limits of the system's devices, energy prices, and demand data, the optimal operation model was solved using the software LINGO [26]. The main flows of the optimal operation are presented in Table 2, in which $E_{\text {grid }}$ represents the net electricity exchanged with the electric grid (negative values mean selling, positive values mean purchase) and $R_{T E S}$ indicates whether the TES is charging (positive values) or discharging (negative values).

The optimal operation of the system brings a total cost of $660.8 € /$ day. The production of electricity and heat in the optimal operation of the trigeneration system and the respective energy demands are presented in Fig. 2. The CM operates at full load throughout the day (load factor of $100 \%$ ), providing electricity for the consumer center $E_{d}$ and for internal consumption in the electric chiller $E_{r}$. Natural gas consumption in the CM totals $600.0 € /$ day. In the morning (from hours 1 to 8 ) and in the night (hours 23 and 24), the system sells surplus electricity to the grid; $9.4 \%$ of the electricity produced is sold, resulting in an income of 63.3 $€ /$ day. On the other hand, from hours 9 to 13 and 17 to 22, the system purchases electricity; $13.2 \%$ of the electricity consumed $\left(E_{d}+E_{r}\right)$ comes from the electric grid, leading to a purchasing cost of $115.6 € /$ day. Hours 14 to 16 are characterized by a match between electric production and consumption $\left(E_{\text {grid }}=0 \mathrm{~kW}\right)$.

Regarding the heat production, $96.6 \%$ of the heat produced by the system is provided by the CM; the remaining $3.4 \%$ is produced by the $\mathrm{AB}$. As can be seen in Fig. 2, the AB operates marginally (load factor of $4 \%$ ) in order to cover heat peak demands of the consumer center, e.g. hours 10, 11, and 20. Fuel-oil consumption in the AB totals 8.6€/day. Energy integration allows the produced heat to be used in the AC for cooling production. In this way, it is possible to cover part of the cooling demand with cogenerated heat. 
Table 2: Optimal operation of the system. Energy flows in $\mathrm{kWh}$ and cost in $€$

\begin{tabular}{|c|c|c|c|c|c|c|c|c|c|c|c|c|c|c|c|c|c|c|c|c|}
\hline Hour & $E_{d}$ & $Q_{d}$ & $\boldsymbol{R}_{d}$ & $\boldsymbol{E}_{\text {grid }}$ & $F_{c}$ & $W_{c}$ & $W_{c c}$ & $Q_{c}$ & $Q_{c c}$ & $Q_{c l}$ & $F_{a}$ & $Q_{a}$ & $Q_{r}$ & $\boldsymbol{R}_{q}$ & $E_{r}$ & $\boldsymbol{R}_{e}$ & $R_{T E S}$ & $\boldsymbol{R}_{S}$ & $S r_{f}$ & Cost \\
\hline 1 & 253.6 & 168.4 & 0.0 & -96.4 & 1000 & 350 & 253.6 & 400 & 400 & 0 & 0.0 & 0.0 & 231.6 & 144.8 & 0.0 & 0.0 & 144.8 & 2.4 & 385.7 & 17.3 \\
\hline 2 & 247.0 & 0.0 & 0.0 & -103.0 & 1000 & 350 & 247.0 & 400 & 400 & 0 & 0.0 & 0.0 & 400.0 & 250.0 & 0.0 & 0.0 & 250.0 & 3.9 & 631.9 & 16.8 \\
\hline 3 & 241.7 & 0.0 & 0.0 & -108.3 & 1000 & 350 & 241.7 & 400 & 400 & 0 & 0.0 & 0.0 & 400.0 & 250.0 & 0.0 & 0.0 & 250.0 & 6.3 & 875.6 & 16.3 \\
\hline 4 & 237.7 & 0.0 & 0.0 & -112.3 & 1000 & 350 & 237.7 & 400 & 400 & 0 & 0.0 & 0.0 & 400.0 & 250.0 & 0.0 & 0.0 & 250.0 & 8.8 & 1116.8 & 16.0 \\
\hline 5 & 253.6 & 0.0 & 0.0 & -96.4 & 1000 & 350 & 253.6 & 400 & 400 & 0 & 0.0 & 0.0 & 400.0 & 250.0 & 0.0 & 0.0 & 250.0 & 11.2 & 1355.6 & 17.3 \\
\hline 6 & 262.9 & 0.0 & 0.0 & -87.1 & 1000 & 350 & 262.9 & 400 & 400 & 0 & 0.0 & 0.0 & 400.0 & 250.0 & 0.0 & 0.0 & 250.0 & 13.6 & 1592.1 & 18.0 \\
\hline 7 & 286.8 & 168.4 & 0.0 & $\begin{array}{l}-63.2 \\
\end{array}$ & 1000 & 350 & 286.8 & 400 & 400 & 0 & 0.0 & 0.0 & 231.6 & 144.8 & 0.0 & 0.0 & 144.8 & 15.9 & 1720.9 & 19.9 \\
\hline 8 & 324.0 & 244.0 & 0.0 & -6.1 & 1000 & 350 & 343.9 & 400 & 400 & 0 & 0.0 & 0.0 & 156.0 & 97.5 & 19.9 & 99.4 & 196.9 & 17.2 & 1900.6 & 24.5 \\
\hline 9 & 377.1 & 378.0 & 0.0 & 27.1 & 1000 & 350 & 350.0 & 400 & 400 & 0 & 0.0 & 0.0 & 22.0 & 13.7 & 0.0 & 0.0 & 13.7 & 19.0 & 1895.3 & 27.7 \\
\hline 10 & 468.7 & 570.5 & 0.0 & 118.7 & 1000 & 350 & 350.0 & 400 & 400 & 0 & 213.1 & 170.5 & 0.0 & 0.0 & 0.0 & 0.0 & 0.0 & 19.0 & 1876.3 & 41.1 \\
\hline 11 & 494.0 & 446.8 & 0.0 & 144.0 & 1000 & 350 & 350.0 & 400 & 400 & 0 & 58.5 & 46.8 & 0.0 & 0.0 & 0.0 & 0.0 & 0.0 & 18.8 & 1857.6 & 40.6 \\
\hline 12 & 454.1 & 309.3 & 0.0 & 104.1 & 1000 & 350 & 350.0 & 400 & 400 & 0 & 0.0 & 0.0 & 90.7 & 56.7 & 0.0 & 0.0 & 56.7 & 18.6 & 1895.7 & 35.4 \\
\hline 13 & 369.1 & 202.8 & 0.0 & 19.1 & 1000 & 350 & 350.0 & 400 & 400 & 0 & 0.0 & 0.0 & 197.2 & 123.3 & 0.0 & 0.0 & 123.3 & 19.0 & 2000.0 & 26.9 \\
\hline 14 & 325.3 & 405.5 & 719.8 & 0.0 & 1000 & 350 & 350.0 & 400 & 400 & 0 & 6.9 & 5.5 & 0.0 & 0.0 & 24.7 & 123.4 & -596.4 & 20.0 & 1383.6 & 25.1 \\
\hline 15 & 313.4 & 319.6 & 644.0 & 0.0 & 1000 & 350 & 350.0 & 400 & 400 & 0 & 0.0 & 0.0 & 80.4 & 50.2 & 36.6 & 183.2 & -410.6 & 13.8 & 959.1 & 25.0 \\
\hline 16 & 338.6 & 299.0 & 698.2 & 0.0 & 1000 & 350 & 350.0 & 400 & 400 & 0 & 0.0 & 0.0 & 101.0 & 63.1 & 11.4 & 57.0 & -578.0 & 9.6 & 371.5 & 25.0 \\
\hline 17 & 414.3 & 240.6 & 614.4 & 112.4 & 1000 & 350 & 350.0 & 400 & 400 & 0 & 0.0 & 0.0 & 159.4 & 99.7 & 48.1 & 240.7 & -274.0 & 3.7 & 93.7 & 36.2 \\
\hline 18 & 468.7 & 299.0 & 359.0 & 168.7 & 1000 & 350 & 350.0 & 400 & 400 & 0 & 0.0 & 0.0 & 101.0 & 63.1 & 50.0 & 250.0 & -45.8 & 0.9 & 47.0 & 41.9 \\
\hline 19 & 452.8 & 405.5 & 296.5 & 152.8 & 1000 & 350 & 350.0 & 400 & 400 & 0 & 6.9 & 5.5 & 0.0 & 0.0 & 50.0 & 250.0 & -46.5 & 0.5 & 0.0 & 40.4 \\
\hline 20 & 455.5 & 508.6 & 243.3 & 154.1 & 1000 & 350 & 350.0 & 400 & 400 & 0 & 135.8 & 108.6 & 0.0 & 0.0 & 48.7 & 243.3 & 0.0 & 0.0 & 0.0 & 43.1 \\
\hline 21 & 418.3 & 405.5 & 247.9 & 117.8 & 1000 & 350 & 350.0 & 400 & 400 & 0 & 6.9 & 5.5 & 0.0 & 0.0 & 49.6 & 247.9 & 0.0 & 0.0 & 0.0 & 36.9 \\
\hline 22 & 361.2 & 319.6 & 177.0 & 36.5 & 1000 & 350 & 350.0 & 400 & 400 & 0 & 0.0 & 0.0 & 80.4 & 50.2 & 25.3 & 126.7 & 0.0 & 0.0 & 0.0 & 28.7 \\
\hline 23 & 308.1 & 240.6 & 0.0 & -41.9 & 1000 & 350 & 308.1 & 400 & 400 & 0 & 0.0 & 0.0 & 159.4 & 99.7 & 0.0 & 0.0 & 99.7 & 0.0 & 99.7 & 21.6 \\
\hline 24 & 273.5 & 168.4 & 0.0 & -76.5 & 1000 & 350 & 273.5 & 400 & 400 & 0 & 0.0 & 0.0 & 231.6 & 144.8 & 0.0 & 0.0 & 144.8 & 1.0 & 243.4 & 18.9 \\
\hline Day & 8400.0 & 6100.0 & 4000.0 & 364.3 & 24000 & 8400 & 7608.8 & 9600 & 9600 & 0 & 428.0 & 342.4 & 3842.4 & 2401.5 & 364.3 & 1821.5 & 223.0 & 223.0 & 22302.0 & 660.8 \\
\hline
\end{tabular}



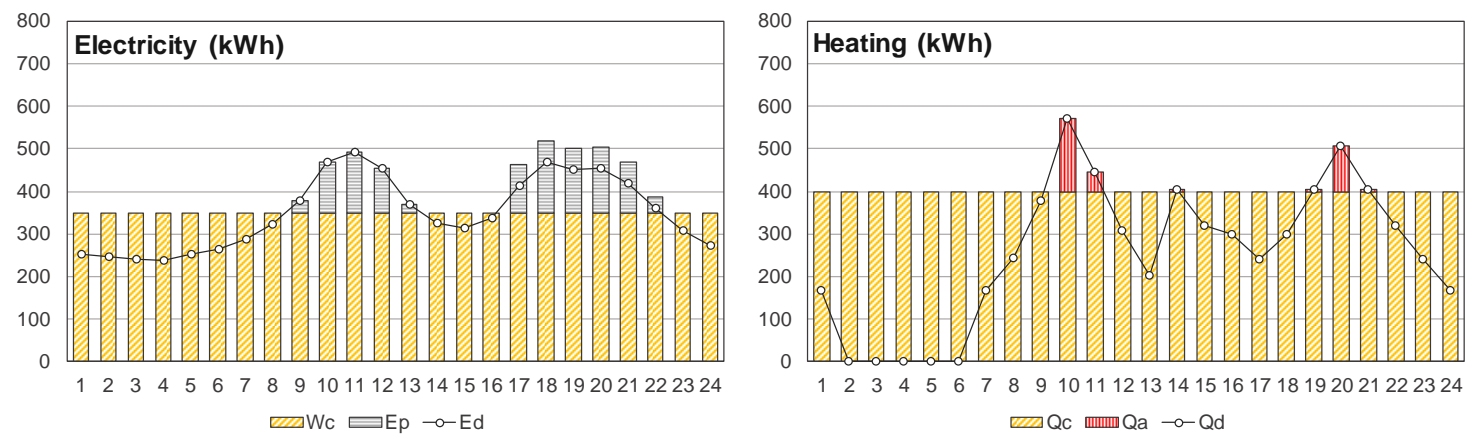

Fig. 2: Electricity (left) and heat (right) flows in the optimal operation.

Fig. 3 shows the cooling production and demand, and the energy stored at the end of each hourly period in the optimal operation of the trigeneration system. Even though cooling is only required by the consumer center between hours 14 and 22, its production also takes place at other hours to charge the TES. Considering all the cooling produced by the system, 56.9\% corresponds to the production in the AC (load factor of $40 \%$ ), while $43.1 \%$ corresponds to the production in the EC (load factor of 30\%). Charging of the TES begins at hour 23 of the previous day. By the time cooling demand starts (hour 14), the TES is fully charged with $2000 \mathrm{kWh}$. Discharging takes place from hour 14 to 19; considering the daily cooling demand, almost half of it is supplied by the TES, meaning that it was produced at a different previous hour.
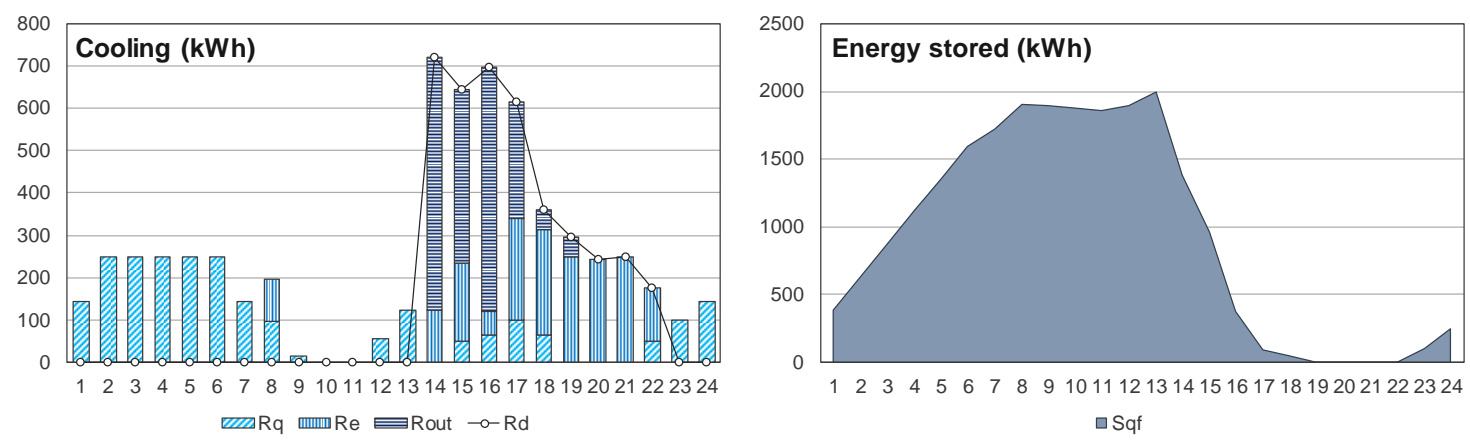

Fig. 3: Cooling flows (left) and energy stored at the end of each hourly period (right) in the optimal operation.

The thermal energy storage unit allows to decouple production from consumption. For this reason, the excess heat produced by the CM (hours 1 to $9,12,13,23$ and 24) can be fully exploited in the AC for cooling production and storage instead of wasted to the environment. In fact, there is no dissipation of cogenerated heat to the environment $\left(Q_{c l}=0 \mathrm{kWh}\right)$. The stored cooling will displace the operation of the EC, reducing the internal electricity consumption and thus resulting in more electricity available for selling or less electricity required to purchase.

\section{$5 \quad$ Marginal cost analysis}

Thermoeconomics combines thermodynamic principles with economic analysis, aiming at revealing opportunities of energy and cost savings in the analysis, diagnosis, and optimization of energy conversion systems that are not available through conventional methods [27], [28]. Obtaining unit costs of internal flows and final products of energy systems is a cornerstone of several thermoeconomic methodologies that have been presented in the literature [19].

Three different approaches to determine the unit costs of internal flows and final products of a simple trigeneration system were presented in [29], namely marginal cost analysis, valuation of products according to their market prices, and internal costs calculation. It was concluded that the calculation method must be selected based on the specific objectives of the analysis.

It is important to distinguish between unit (or average) and marginal costs: Unit cost is the total cost divided by the total quantity produced, while marginal cost is the additional cost associated with an additional 
quantity of something. The issue is that unit costs do not explain the reasons for the optimal operation mode of the plant, nor do they provide information about the behavior of the system's operation given a change in external circumstances (e.g. energy demand changes). Furthermore, unit cost calculation in energy systems with joint production, such as trigeneration systems, can only be achieved by stablishing arbitrary cost allocation rules.

On the other hand, marginal costs can give valuable insight into process optimization, indicating constraints that could be changed to improve the objective function, product pricing as well as business decisions [19], [22]. Because marginal costs are intrinsically related to the operation of the system, a "marginal path" can be traced, linking the point at which the marginal change is required (e.g. consumer center's energy demand), via one or more items of the system's equipment, to the system boundary where changes in the fuel and/or electricity purchases can be evaluated; the term "marginal path" is generally reserved to the one which incurs the smallest marginal cost [30].

Marginal costs are difficult to calculate given the several possibilities of production paths, especially in systems with high level of energy integration. Computational tools facilitate the calculation of marginal costs and the analysis of the influences of changes in the input data.

Together with the optimal operation of the system, the LINGO solution report provides a dual price figure for each constraint of the model. This dual price figure indicates the amount by which the objective function (in this case, the daily operation cost) would change as the constant term of the constraint is increased by one unit. If a constraint expresses the production of a flow, then its dual price can be interpreted as the marginal $\cos t \lambda$ of this flow.

Table 3 presents for each hourly period the dual prices of selected constraints from the mathematical model described in Section 3, namely equipment constraints CM_Wmax (Eq. (3)), CM_W (Eq. (8)), CM_Q (Eq. (9)), AC_R (Eq. (11)), and EC_R (Eq. (12)), and balance equations P (Eq. (17)), Q (Eq. (19)), and R (Eq. (20)). The following sections present a detailed interpretation of the dual prices associated with the system's constraints and final products.

\subsection{Marginal costs of the final products}

The dual prices of constraints $\mathrm{P}, \mathrm{Q}$, and $\mathrm{R}$ can be interpreted as the marginal costs of the electricity $\lambda E_{d}$, heat $\lambda Q_{d}$, and cooling $\lambda R_{d}$, respectively, as can be seen in Table 3. Examples of the interpretation of the marginal costs for selected hours are presented in the following paragraphs.

Figures 4, 5, and 6 graphically explain the "marginal paths" of the final products of the trigeneration system for hours 8, 9, and 15, respectively. In the three Figures, the "marginal paths" of the electricity, heat, and cooling are represented by bold, dashed, and dotted lines, respectively. It should be noted that marginal costs are evaluated individually, therefore the Figures 4, 5, and 6 present the marginal costs of each of the final products and not of the production of all three at the same time.

\section{Hour 8: Of simultaneous energy service production and supply}

At hour 8 electricity is sold to the electric grid, the $\mathrm{CM}$ is operating at full load, and cooling is produced in both the $\mathrm{AC}$ and EC. The marginal cost of the electricity is $\lambda E_{d}=0.080 € / \mathrm{kWh}$, which indicates that if an additional unit of electricity is required, one less unit will be sold to the market; thus, $\lambda E_{d}$ can be interpreted as the selling price $p_{e s}\left(\lambda E_{d}=1 \cdot p_{e s}=0.080 € / \mathrm{kWh}\right)$. The marginal cost of the heat $\lambda Q_{d}=0.010 € / \mathrm{kWh}$ can be interpreted as follows: If an additional unit of heat is required, one less unit will be directed to the AC, resulting in $1 . \mathrm{COP}_{q}=0.625 \mathrm{kWh}$ less of cooling produced; the depletion will be covered by the EC with $0.625 / C O P_{e}=0.125 \mathrm{kWh}$ less of electricity available to be sold to the electric grid $\left(\lambda Q_{d}=0.125 \cdot p_{e s}=0.010\right.$ $€ / \mathrm{kWh}$ ). The marginal cost of cooling is $\lambda R_{d}=0.016 € / \mathrm{kWh}$, which means that the additional unit of cooling will be provided by the EC with $1 / C O P_{e}=0.200 \mathrm{kWh}$ of electricity at selling price $\left(\lambda R_{d}=0.200 \cdot p_{e s}=0.016\right.$ $€ / \mathrm{kWh})$. 
Table 3: Dual prices of selected constraints, in $€ / \mathrm{kWh}$

\begin{tabular}{|c|c|c|c|c|c|c|c|c|}
\hline \multirow{2}{*}{ Hour } & \multicolumn{8}{|c|}{ Constraints } \\
\hline & CM_Wmax & CM_W & CM_Q & AC_R & EC_R & $P\left(\lambda E_{d}\right)$ & $\mathbf{Q}\left(\lambda \mathbf{Q}_{\mathrm{d}}\right)$ & $\mathbf{R}\left(\lambda \mathbf{R}_{\mathbf{d}}\right)$ \\
\hline 1 & -0.0192 & 0.0608 & 0.0093 & 0.0149 & - & 0.0800 & 0.0093 & 0.0149 \\
\hline 2 & -0.0193 & 0.0607 & 0.0094 & 0.0151 & - & 0.0800 & 0.0094 & 0.0151 \\
\hline 3 & -0.0194 & 0.0606 & 0.0095 & 0.0152 & - & 0.0800 & 0.0095 & 0.0152 \\
\hline 4 & -0.0195 & 0.0605 & 0.0096 & 0.0154 & - & 0.0800 & 0.0096 & 0.0154 \\
\hline 5 & -0.0197 & 0.0603 & 0.0097 & 0.0155 & - & 0.0800 & 0.0097 & 0.0155 \\
\hline 6 & -0.0198 & 0.0602 & 0.0098 & 0.0157 & - & 0.0800 & 0.0098 & 0.0157 \\
\hline 7 & -0.0199 & 0.0601 & 0.0099 & 0.0158 & - & 0.0800 & 0.0099 & 0.0158 \\
\hline 8 & -0.0200 & 0.0600 & 0.0100 & 0.0160 & 0.0160 & 0.0800 & 0.0100 & 0.0160 \\
\hline 9 & -0.0401 & 0.0599 & 0.0101 & 0.0162 & - & 0.1000 & 0.0101 & 0.0162 \\
\hline 10 & -0.0571 & 0.0429 & 0.0250 & - & - & 0.1000 & 0.0250 & 0.0163 \\
\hline 11 & -0.0571 & 0.0429 & 0.0250 & - & - & 0.1000 & 0.0250 & 0.0165 \\
\hline 12 & -0.0405 & 0.0595 & 0.0104 & 0.0167 & - & 0.1000 & 0.0104 & 0.0167 \\
\hline 13 & -0.0406 & 0.0594 & 0.0105 & 0.0168 & - & 0.1000 & 0.0105 & 0.0168 \\
\hline 14 & -0.0542 & 0.0429 & 0.0250 & - & 0.0194 & 0.0970 & 0.0250 & 0.0194 \\
\hline 15 & -0.0406 & 0.0574 & 0.0123 & 0.0196 & 0.0196 & 0.0980 & 0.0123 & 0.0196 \\
\hline 16 & -0.0417 & 0.0573 & 0.0124 & 0.0198 & 0.0198 & 0.0990 & 0.0124 & 0.0198 \\
\hline 17 & -0.0429 & 0.0571 & 0.0125 & 0.0200 & 0.0200 & 0.1000 & 0.0125 & 0.0200 \\
\hline 18 & -0.0430 & 0.0570 & 0.0126 & 0.0202 & 0.0200 & 0.1000 & 0.0126 & 0.0202 \\
\hline 19 & -0.0571 & 0.0429 & 0.0250 & - & 0.0200 & 0.1000 & 0.0250 & 0.0204 \\
\hline 20 & -0.0571 & 0.0429 & 0.0250 & - & 0.0200 & 0.1000 & 0.0250 & 0.0200 \\
\hline 21 & -0.0571 & 0.0429 & 0.0250 & - & 0.0200 & 0.1000 & 0.0250 & 0.0200 \\
\hline 22 & -0.0429 & 0.0571 & 0.0125 & 0.0200 & 0.0200 & 0.1000 & 0.0125 & 0.0200 \\
\hline 23 & -0.0190 & 0.0610 & 0.0091 & 0.0146 & - & 0.0800 & 0.0091 & 0.0146 \\
\hline 24 & -0.0191 & 0.0609 & 0.0092 & 0.0148 & - & 0.0800 & 0.0092 & 0.0148 \\
\hline
\end{tabular}

Alternative production paths can be identified in Fig. 4 and proved to be more costly than their respective "marginal paths". For example, the additional unit of heat could be supplied by the AB with the consumption of $1 / \eta_{q}=1.250 \mathrm{kWh}$ of fuel-oil valued at price $p_{f a}=0.020 € / \mathrm{kWh}$, thus resulting in a marginal cost of $0.025 € / \mathrm{kWh}$, which is more than double the $\lambda Q_{d}$. The additional cooling could be supplied by the $\mathrm{AC}$ with $1 / C O P_{q}=1.6 \mathrm{kWh}$ of heat from the $\mathrm{AB}$, which requires $1.6 / \eta_{q}=2 \mathrm{kWh}$ of fuel-oil at price $p_{f a}=$ $0.020 € / \mathrm{kWh}$, thus resulting in a marginal cost of $0.040 € / \mathrm{kWh}$, which is more than double the $\lambda R_{d}$; this shows that cooling production in the EC with electricity (either at purchasing or selling price) is more profitable than in the $\mathrm{AC}$ with heat from the $\mathrm{AB}$. This is why whenever cooling is required at hour 8 it is produced in the EC rather than in the AC.

Less obvious production paths can be traced by including the TES and connecting the system's operation at hour 8 to other hourly periods. However, these would also prove to be more costly than the "marginal paths" obtained. Examples of how and why production should be advanced or postponed by using the TES to supply cheaper energy services are given below for hours 9 and 15 . 


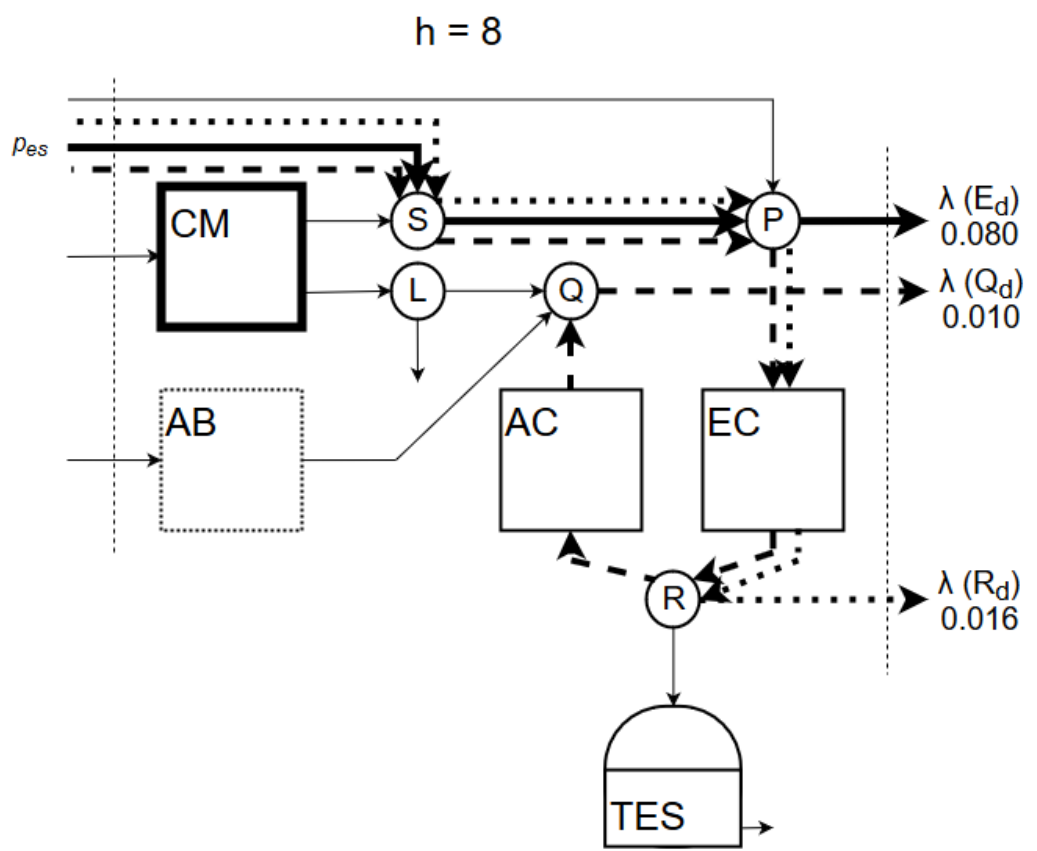

Fig. 4: Marginal paths for hour 8.

Hour 9: Of why energy service production should be advanced

Even though the TES is charging at hour 8, it does not directly affect the marginal costs of the final products of the trigeneration system at that hour, i.e. it is not included in the "marginal path". By contrast, Fig. 5 shows that the "marginal paths" of the heat and cooling supplied at hour 9 are linked to the system's operation at hour 8 through the TES.

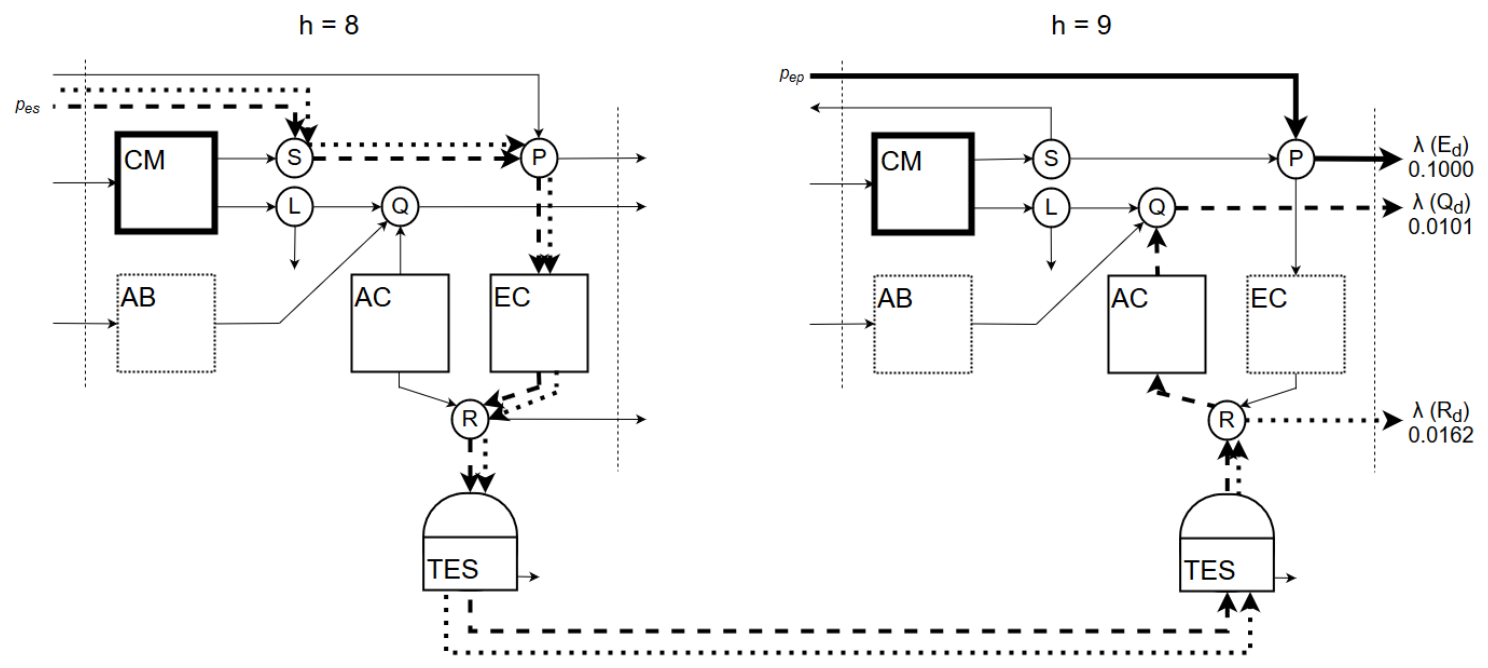

Fig. 5: Marginal paths for hour 9.

At hour 9, the marginal cost of the electricity is $\lambda E_{d}=0.1000 € / \mathrm{kWh}$, which indicates that if an additional unit of electricity is required, it will be purchased from the electric grid at purchasing price $\left(\lambda E_{d}=1 \cdot p_{e p}=\right.$ $0.1000 € / \mathrm{kWh}$ ). In this case, both the purchase and the supply of the marginal electricity take place within hour 9 .

On the other hand, the "marginal paths" of the heat and cooling include the TES, meaning that production is displaced in time. The marginal cost of the heat $\lambda Q_{d}=0.0101 € / \mathrm{kWh}$ can be interpreted as follows: If an additional unit of heat is required, one less unit will be directed to the $\mathrm{AC}$, resulting in $1 \cdot C O P_{q}=0.625 \mathrm{kWh}$ less of cooling produced; because the TES is being charged at hour $9,0.625 \mathrm{kWh}$ less of cooling will be 
stored. The depletion must be offset at hour 8, when cooling can be produced in the EC with electricity at selling price $p_{e s}$. However, because of energy losses in the TES, more than $0.625 \mathrm{kWh}$ of cooling must be produced and stored at hour 8. Given the required discharge at hour $h, R_{\text {out }}(h)$, Eq. (22) allows to determine how much cooling must be produced and stored at hour $k, R_{\text {in }}(k)$.

$$
R_{\text {out }}(h)=R_{\text {in }}(k) \cdot\left(1-\tau_{T E S}\right)^{(h-k)}
$$

It follows that to compensate for the lack of $0.6250 \mathrm{kWh}$ of cooling at hour $9,0.6313 \mathrm{kWh}$ of cooling must be produced and stored at hour 8 with the consumption of $0.1263 \mathrm{kWh}$ of electricity at selling price $\left(\lambda Q_{d}=\right.$ $0.1263 \cdot p_{e s}=0.0101 € / \mathrm{kWh}$ ). The same reasoning can be applied to the marginal of cooling $\lambda R_{d}=0.0162$ $€ / \mathrm{kWh}$ : Supplying an additional unit of cooling at hour 9 reduces storage in the same amount, which must be compensated by producing $1.0101 \mathrm{kWh}$ of cooling $(1 \mathrm{kWh}+$ energy losses $)$ at hour 8 with $0.2020 \mathrm{kWh}$ of electricity at selling price $\left(\lambda R_{d}=0.2020 \cdot p_{e s}=0.0162 € / \mathrm{kWh}\right)$.

Alternative (and more costly) production paths can be identified in Fig. 5, similarly to those explained for hour 8 (Fig. 4). It becomes clear that even though at hour 9 the devices AB, AC, and EC are able to supply the marginal energy services, production must be advanced to hour 8 in order to achieve lower costs.

Hour 15: Of why energy service production should be postponed

As shows Fig. 6, the "marginal paths" of electricity, heat, and cooling supplied at hour 15 are linked to the system's operation at hour 17 through the TES.

$h=15$

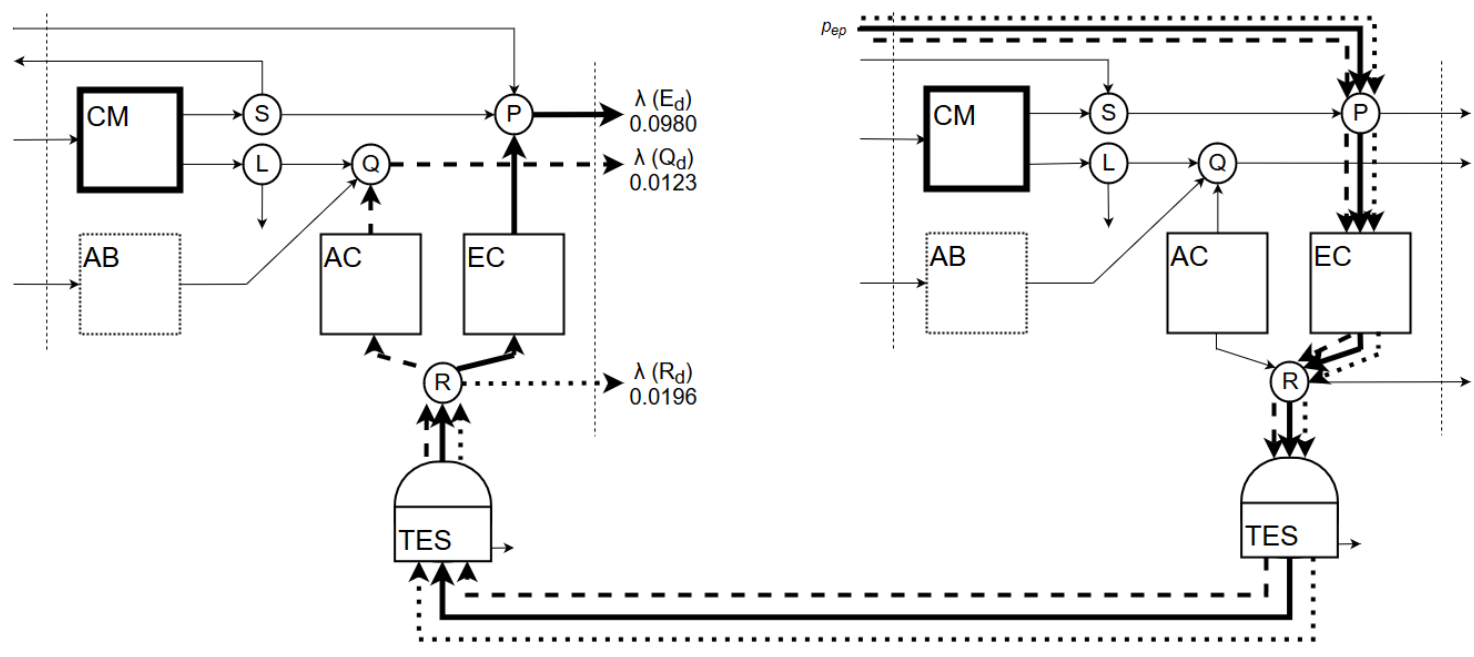

Fig. 6: Marginal paths for hour 15.

At hour 15, the CM operates at full load, both AC and EC operate at partial load, and the TES is discharging (discharging takes place from hours 14 to 19). Moreover, there is neither purchase nor selling of electricity. The marginal cost of the electricity $\lambda E_{d}=0.0980 € / \mathrm{kWh}$ can be interpreted as follows: If an additional unit of electricity is required at hour 15 , the system will reduce EC consumption by $1 \mathrm{kWh}$ and compensate the lack of $1 \cdot C O P_{e}=5 \mathrm{kWh}$ of cooling by increasing the discharge from the TES. Consequently, there will be less cooling stored in the following hours, which will ultimately affect the system's operation at the end of the discharging period (hour 19). Therefore, that is the most appropriate time for the compensation to take place. Nevertheless, at hour 19 the EC operates at full load and thus its production cannot be increased. The same is true for hour 18. Finally, the production in the EC must take place at hour 17 with electricity purchased from the grid. It is interesting to notice that, because now storage time has reduced from five hours (from 14 to 19) to two (from 17 to 19), the production will be smaller than the corresponding consumption. The exact figure can be determined by Eq. (22), whose application in this particular case of postponed production gives how much energy must be produced at hour $k R_{\text {in }}(k)$ in order to compensate for a discharge at a previous hour $h R_{\text {out }}(h)$. 
It follows that to compensate for the discharge $R_{\text {out }}(15)=5 \mathrm{kWh}$ at hour $15, R_{\text {in }}(17)=4.9050 \mathrm{kWh}$ of cooling must be produced at hour 17; the corresponding electricity consumption in the EC $4.9050 / \mathrm{COP}_{e}=0.9810$ $\mathrm{kWh}$ valued at purchasing price gives the marginal cost of the electricity supplied at hour $15\left(\lambda E_{d}=\right.$ $\left.0.9810 \cdot p_{e p}=0.0980 € / \mathrm{kWh}\right)$.

Thus, the correct interpretation of the arrows in Fig. 6 is that production is being postponed by increasing the discharge of energy that is already stored, and not that energy is being stored from hour 17 to hour 15.

The marginal costs of the heat $\lambda Q_{d}=0.0123 € / \mathrm{kWh}$ and cooling $\lambda R_{d}=0.0196 € / \mathrm{kWh}$ can be understood following the same logic. By consuming an additional unit of heat at hour $15,1 \cdot C O P_{q}=0.625 \mathrm{kWh}$ less of cooling is produced, which must be compensated by increasing the discharge from the TES. At hour 17, $0.6125 \mathrm{kWh}$ of cooling must be produced in the EC with $0.1225 \mathrm{kWh}$ of purchased electricity $\left(\lambda Q_{d}=\right.$ $0.1225 \cdot p_{e p}=0.0123 € / \mathrm{kWh}$ ). Similarly, the additional consumption of $1 \mathrm{kWh}$ of cooling at hour 15 increases consumption of purchased electricity in the EC at hour 17 by $0.1960 \mathrm{kWh}\left(\lambda R_{d}=0.1960 \cdot p_{e p}=0.0196\right.$ $€ / \mathrm{kWh})$.

\subsection{Cyclical view of the operation with TES}

Both hours 9 and 15 use the TES to shift marginal production in time. However, while the shift that takes place from hour 9 to hour 8 advances production, the one from hour 15 to 17 postpones it. There lies a fundamental difference. By advancing production the storage time increases and so do the energy losses. Therefore, the production that takes place at hour 8 is higher than the corresponding supply at hour 9 (production at hour $8=$ marginal supply at hour $9+$ energy losses). This situation can only be profitable if: (i) the energy resource is cheaper enough at a previous hour than at the hour of supply as to compensate for energy losses (e.g. hour $8 p_{e s}$ versus hour $9 p_{e p}$ ), or (ii) it is more profitable to support a higher operation cost due to energy losses than to increase installed capacity. On the other hand, by postponing production the storage time decreases and so do the energy losses. Therefore, production at hour 17 will be smaller than the corresponding supply at hour 15 (production at hour $17=$ marginal supply at hour 15 - energy losses), and so $\lambda(15)<\lambda(17)$.

With these key hours explained, a more general approach to the marginal costs of the 24-hour operation of the system can be taken. Fig. 7, Fig. 8, and Fig. 9 present the marginal costs from Table 3 of the electricity, heat, and cooling, respectively, and highlight the interconnection between the hourly periods through the TES. The enclosed numbers represent the operation hours, while the numbers on the outside express the corresponding marginal costs in $€ / \mathrm{kWh}$.

In each Figure, gray scales are used to represent different origins of the marginal final products of the trigeneration system. In the case of the electricity (Fig. 7), periods in white are those in which the marginal electric demand is covered by internal production at the same hour, that is, there is no shift in production. Therefore, following the same logic as explained for hour 8 , the marginal cost of electricity in such periods can be interpreted as the selling price $p_{e s}=0.080 € / \mathrm{kWh}$. In black periods the marginal cost of the electricity can be interpreted as the purchasing price $p_{e p}=0.100 € / \mathrm{kWh}$ because the marginal electricity comes from the electric grid, as explained for hour 9. Lastly, light gray periods are those in which it is possible to postpone production to hour 17 , as explained for hour 15 . It can be seen that the marginal costs of the electricity increase from hours 14 to 17 , as the time difference between the supply and the corresponding production shortens. 


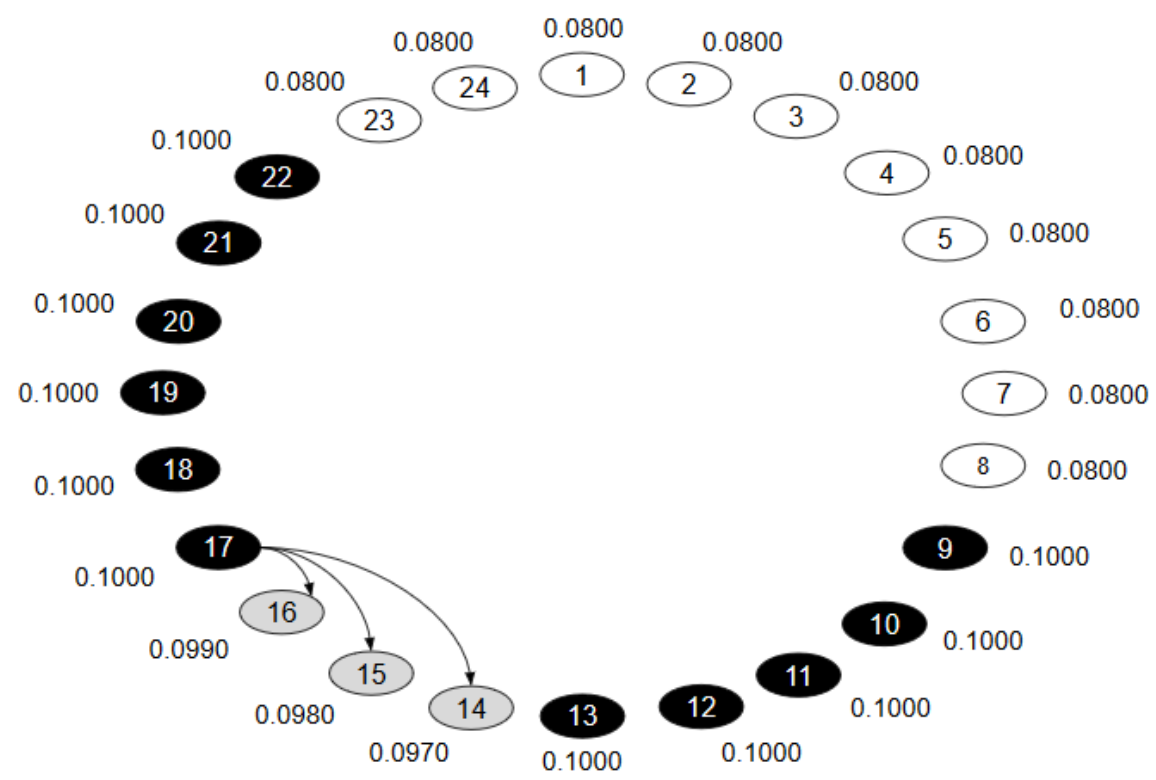

Fig. 7: Hourly marginal costs of the electricity, in $€ / \mathrm{kWh}$.

Regarding the heat production (Fig. 8), the same concepts as described for the white and light gray periods in Fig. 7 apply. In the case of white periods, the marginal cost varies according to the different resources consumed: (i) at hour 8, the marginal cost of the heat is related to the production of cooling in the EC with electricity at selling price $p_{e s}=0.080 € / \mathrm{kWh}$; (ii) hours 17 and 22 follow the same logic as hour 8 but with electricity purchased from the electric grid at $p_{e p}=0.100 € / \mathrm{kWh}$; (iii) for the rest of the white periods, the marginal heat is produced by the $\mathrm{AB}$ at $p_{f a} / \eta_{q}=0.025 € / \mathrm{kWh}$. The marginal cost of the heat in periods that postpone production (light gray periods) or advance it (dark gray periods) are related to the price of the resource consumed in the period in which the production takes place. For example, hours 1 to 7, 23, and 24 postpone production to hour 8 , in which electricity is sold at $p_{e s}=0.080 € / \mathrm{kWh}$, so their marginal costs will be lower than $\lambda Q_{d}(8)=0.0100 € / \mathrm{kWh}$. Likewise, hours 15 and 16 advance consumption from hour 17, when the system purchases electricity at $p_{e p}=0.100 € / \mathrm{kWh}$, so their marginal costs will be lower than $\lambda Q_{d}(17)=$ $0.0125 € / \mathrm{kWh}$. The same considerations are valid for the marginal costs of cooling (Fig. 9).

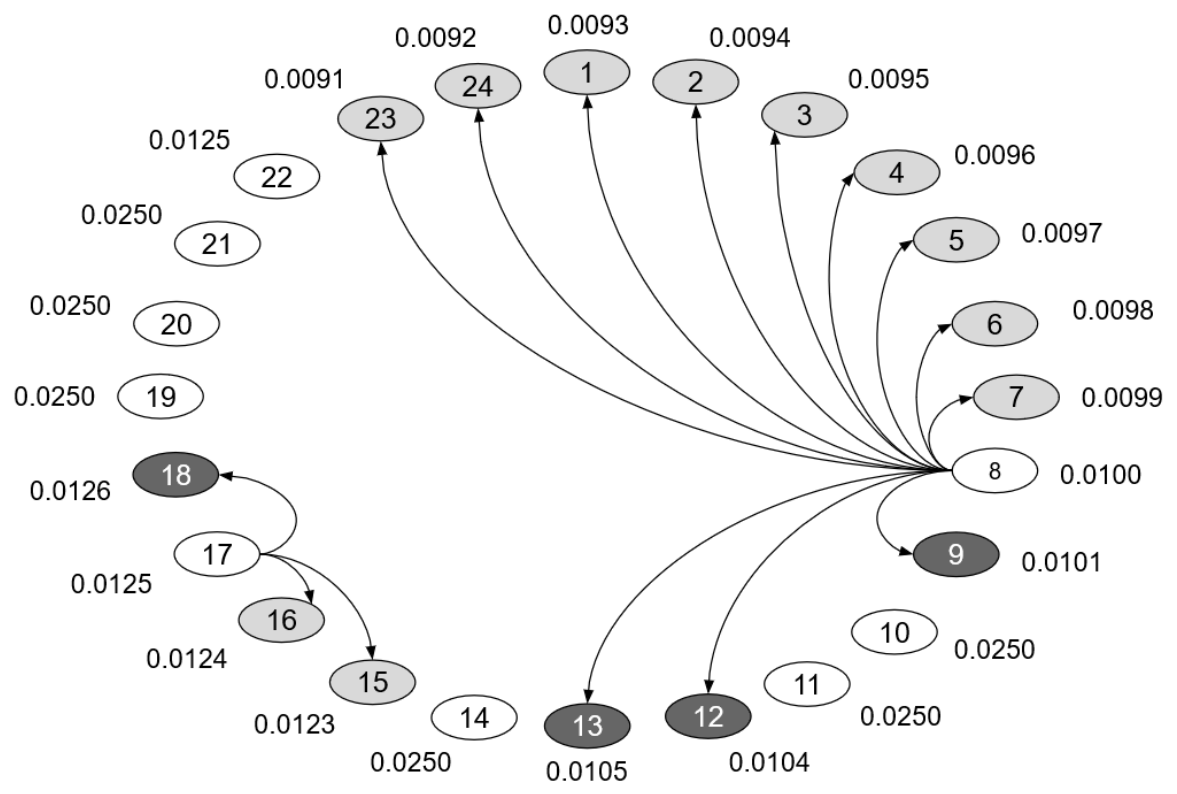

Fig. 8: Hourly marginal costs of the heat, in $€ / \mathbf{k W h}$. 


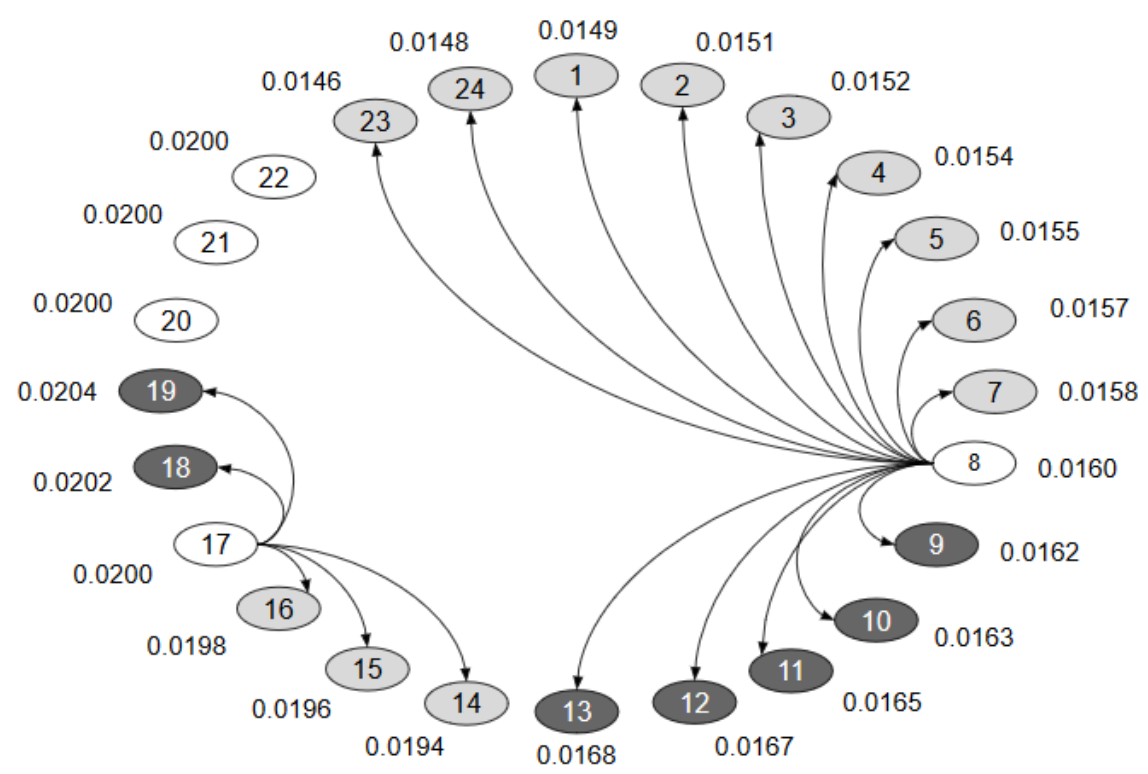

Fig. 9: Hourly marginal costs of the cooling, in $€ / \mathrm{kWh}$.

It becomes clear that even though only a TES for cooling is included, the thermal integration in the trigeneration system allows to extend the benefits of the storage to the other utilities, e.g. electricity and heat.

\subsection{Internal constraints}

The marginal costs of the internal flows can be obtained by interpreting the dual prices corresponding to constraints (3)-(21) of the optimization model. The following paragraphs provide examples of interpretation of the dual prices obtained, some of which are shown in Table 3.

\section{Capacity limits}

Capacity limits impose an upper limit to the device's production. Increasing the right-hand side of the constraint (or the constant term) allows the device to increase its maximum production. Therefore, the associated dual price can be interpreted as the marginal cost of producing an additional unit of product. Of course, only active restrictions present non-zero dual prices (i.e. only when the corresponding device operates at full load, otherwise it would make no difference to increase installed capacity). In fact, dual prices of constraints AB_Qmax (Eq. (4)) and AC_Rqmax (Eq. (5)) are always zero because neither device reaches its maximum capacity. Moreover, it should be noted that the analysis carried out in this paper only considers operation costs and not capital costs.

Constraint CM_Wmax (Eq. (3)) limits the production of electricity $W_{c}$ in the CM to a maximum $W_{\max }$. Increasing $W_{\max }$ by one unit leads to:

- An increase in the production of electricity of $1 \mathrm{kWh}$;

- An increase in the consumption of natural gas of $1 / \alpha_{w}=2.8570 \mathrm{kWh}$;

- An increase in the production of cogenerated heat of $\alpha_{q} / \alpha_{w}=1.1428 \mathrm{kWh}$.

While the additional consumption of natural gas increases the total operation cost, producing more electricity and cogenerated heat creates savings that can be valued at the marginal costs of electricity and heat, respectively. For each hourly period, the marginal cost associated with restriction CM_Wmax can be interpreted as the economic impact that the three effects have on the objective function:

$$
\lambda C M_{-} W \max (h)=2.8570 \cdot p_{f c}-1 \cdot \lambda E_{d}(h)-1.1428 \cdot \lambda Q_{d}(h)
$$


For example, at hour 8 the cost associated with the increase in the consumption of natural gas is $2.8570 \cdot p_{f c}$ $=0.0714 € / \mathrm{kWh}$, the increase in electricity and cogenerated heat productions allow for savings of $1 \cdot \lambda E_{d}(8)$ $=0.0800 € / \mathrm{kWh}$ and $1.1428 \cdot \lambda Q_{d}(8)=0.0114 € / \mathrm{kWh}$, respectively. This results in a decrease of 0.0200 $€ / \mathrm{kWh}$ in the total operation cost. The negative sign in $\lambda C M_{-} \operatorname{Wmax}(8)=-0.0200 € / \mathrm{kWh}$ shows that an increase in the capacity limit $W_{\max }$ would lead to an improvement in the objective function (i.e., reduction of the total operation cost).

The EC operates at full load at hours 18 and 19. At these hours, the dual prices associated with constraint EC_Remax (Eq. (6)) are $-0.0002 € / \mathrm{kWh}$ and $-0.0004 € / \mathrm{kWh}$, respectively. The interpretation is that, because hours 18 and 19 advance production to hour 17, increasing cooling production in the EC by $1 \mathrm{kWh}$ at such hours would decrease production at hour 17. For example, at hour 18 the additional cooling would be produced with $0.2000 \mathrm{kWh}$ of purchased electricity at $p_{e p}=0.1000 € / \mathrm{kWh}$, thus reducing the purchase of electricity at hour 17 by $0.2020 \mathrm{kWh}$. Therefore:

$$
\lambda E C_{\text {Remax }}(18)=0.200 \cdot p_{e p}-0.202 \cdot p_{e p}=-0.0002 € / k W h
$$

As can be seen, this change results in a reduction of $0.0002 € / \mathrm{kWh}$ in the total operation cost, which is equal to the marginal cost associated with restriction EC_Remax at hour 18.

The constraint Sri_Vol (Eq. (7)) only has a non-zero dual price at hour 14, when the TES is fully charged. At that hour, it would be profitable to be able to store an additional unit of energy, which would allow to increase cooling production and storage at hour 8 (with electricity at $p_{e s}=0.080 € / \mathrm{kWh}$ ) and reduce cooling production at hour 17 (with purchased electricity at $p_{e p}=0.100 € / \mathrm{kWh}$ ).

\section{Production constraints}

Production constraints are associated with the efficiency of production in each device. By increasing the right-hand side of the constraint, either the device consumption increases in order to keep the production unchanged or the production decreases to maintain consumption. Unlike capacity constraints, the marginal cost associated with production constraints have a negative impact on the objective function (i.e. increase the total operation cost).

The constraint CM_W (Eq. (8)) is associated with the efficiency of electricity production in the CM. By increasing the right-hand side of Eq. (8) by one unit, either $W_{c}$ is kept unchanged and $F_{c}$ is increased or $W_{c}$ is decreased and $F_{c}$ is kept constant. It can be demonstrated that the former alternative is more profitable because (i) the electricity from the CM is cheaper than the purchase and selling prices of electricity (if the cost of fuel consumption were allocated entirely to the electricity production, its unit price would be 0.0714 $€ / \mathrm{kWh}$, which is lower than $p_{e p}$ and $p_{e s}$ ), so reducing its production would incur in a greater cost; and (ii) by increasing fuel consumption by $1 / \alpha_{w}=2.8570 \mathrm{kWh}$, the production of cogenerated heat increases accordingly $\alpha_{q} / \alpha_{w}=1.1428 \mathrm{kWh}$, displacing production in another device.

For each hourly period, the marginal cost of constraint CM_W can be interpreted as the economic impacts of the consumed fuel $2.8570 \mathrm{kWh}$, valued at $p_{f_{c}}=0.025 € / \mathrm{kWh}$, and the produced heat $1.1428 \mathrm{kWh}$, valued at the corresponding marginal cost $\lambda Q_{d}(h)$. For example, at hour 8:

$$
\lambda C M_{-} W(8)=2.8570 \cdot p_{f c}-1.1428 \cdot \lambda Q_{d}(8)=0.0600 € / k W h
$$

Constraint CM_Q (Eq. (9)) is associated with the efficiency of production of cogenerated heat in the CM. By increasing the right-hand side of Eq. (9) by one unit, the cogenerated heat $Q_{c}$ would decrease by the same amount. This happens because the consumption of natural gas is defined by the electric production $W_{c}$, which, as explained, remains constant. The lack of cogenerated heat must be compensated by production elsewhere at the corresponding marginal cost $\lambda Q_{d}(h)$.

Whenever the $\mathrm{AB}$ operates, the dual price associated with restriction AB_Q (Eq. (10)) will be that of producing $1 \mathrm{kWh}$ of heat $Q_{a}$, that is $\left(1 / \eta_{q}\right) \cdot p_{f a}=0.0250 € / \mathrm{kWh}$. The interpretation is that by increasing the right-hand side of Eq. (10) by one unit, the AB increases fuel-oil consumption accordingly.

Regarding constraints AC_R (Eq. (11)) and EC_R (Eq. (12)), it can be seen in Table 3 that dual prices are 
only provided when the device operates, as it makes no sense to evaluate the effect of production efficiency in a non-operating device.

Increasing the right-hand side of restriction $\mathrm{AC} \_\mathrm{R}$ by one unit leads to a reduction in the cooling production $R_{q}$, which would have to be compensated by production elsewhere at the corresponding marginal cost $\lambda R_{d}(h)$. This situation takes place because, as explained earlier, it is more profitable to produce cooling in the EC than in the AC. However, by increasing the right-hand side of restriction EC_R by one unit, the production $R_{e}$ is kept constant, while the consumption of electricity is increased by $1 / C O P_{e}=0.200 \mathrm{kWh}$. The marginal cost associated with restriction EC_R can be interpreted as the economic impact of the increase in electricity consumption valued at the marginal cost of the electricity $\left(\lambda E C_{-} R(h)=0.200 \cdot \lambda E_{d}(h)\right)$.

Eq. (13) expresses the energy loss in the TES for each hourly period. The corresponding dual price can be interpreted as the marginal cost of wasting energy in the TES, which will bring the same marginal cost as that of the cooling $\lambda R_{d}(h)$.

\section{Balance constraints}

The dual prices associated with balance constraints can be interpreted as the marginal cost of the corresponding internal product or energy service. Therefore, the dual prices of junctions S (Eq. (16)) and P (Eq. (17)) correspond to the marginal cost of electricity $\lambda E_{d}(h)$, the dual prices of junctions L (Eq. (18)) and $\mathrm{Q}$ (Eq. (19)) correspond to the marginal cost of heat $\lambda Q_{d}(h)$, and the dual price of junction R (Eq. (20)), corresponds to the marginal cost of cooling $\lambda R_{d}(h)$. Further, the dual prices associated with the energy balance in the TES (Eq. (21)) can be interpreted as the marginal cost of cooling $\lambda R_{d}(h)$.

\section{Conclusions}

The optimal operation of a trigeneration system with TES was analyzed in the present paper, aiming at understanding the role of the TES in achieving the optimal solution. The trigeneration system analyzed herein was designed to attend the electricity, heating, and cooling demands of a consumer center. The optimal operation of the system for a representative day composed of 24 hourly periods was obtained by a linear programming model that minimizes the total variable cost. A thermoeconomic analysis based on marginal cost assessment was carried out.

The marginal costs of the internal flows and final products of the system allowed to explain the reason for the operational strategy. Furthermore, it was possible to unravel the marginal cost formation process, tracing the production costs back to the resource consumption. The incorporation of TES added a new dimension to the cost allocation problem: by decoupling production and consumption, it becomes necessary to know not only the device in which production takes place, but also the time. By studying the interconnection between the hourly periods through the TES, it was possible to identify periods in which the system takes advantage of its ability to store energy to achieve a more interesting economic result; namely, there were periods in which consumption was advanced and periods in which consumption was postponed. Despite presenting fundamentally different concepts, both types of periods result in lower operation costs. Understanding the effects of varying production and/or demand in an hourly period is crucial to improving the operational management of the system and, thus, achieving the minimum operational cost.

\section{Acknowledgements}

The authors thank the Spanish Ministry of Economy and Competitiveness for the funding of this work within the framework of project ENE2014-57262-R, with the additional support of the Government of Aragon (Spain) and the European Union Social Fund (FEDER Program). Eduardo Pina acknowledges financial support from Brazil Federal Government/CNPq Science Without Borders Program. 
[1] L. M. Serra, M. A. Lozano, J. Ramos, A. V. Ensinas, and S. A. Nebra, "Polygeneration and efficient use of natural resources," Energy, vol. 34, no. 5, pp. 575-586, May 2009.

[2] P. Mancarella, "MES (multi-energy systems): An overview of concepts and evaluation models," Energy, vol. 65, pp. 1-17, 2014.

[3] EU, "Directive 2010/31/EU of the European Parliament and of the Council of 19 May 2010 on the energy performance of buildings (recast)," Off. J. Eur. Union, pp. 13-35, 2010.

[4] G. Chicco and P. Mancarella, "Distributed multi-generation: A comprehensive view," Renew. Sustain. Energy Rev., vol. 13, no. 3, pp. 535-551, Apr. 2009.

[5] M. A. Lozano, M. Carvalho, and L. M. Serra, "Allocation of economic costs in trigeneration systems at variable load conditions,” Energy Build., vol. 43, no. 10, pp. 2869-2881, 2011.

[6] T. Wakui, H. Kawayoshi, and R. Yokoyama, "Optimal structural design of residential power and heat supply devices in consideration of operational and capital recovery constraints," Appl. Energy, vol. 163, pp. 118-133, Feb. 2016.

[7] D. W. Wu and R. Z. Wang, "Combined cooling, heating and power: A review," Prog. Energy Combust. Sci., vol. 32, no. 5-6, pp. 459-495, Sep. 2006.

[8] M. Liu, Y. Shi, and F. Fang, "Combined cooling, heating and power systems: A survey," Renew. Sustain. Energy Rev., vol. 35, pp. 1-22, 2014.

[9] A. Y. Rong, Y. Su, and R. Lahdelma, "Review of optimization techniques of polygeneration systems for building applications,” IOP Conf. Ser. Earth Environ. Sci., vol. 40, no. 12026, Aug. 2016.

[10] A. N. Ünal, S. Ercan, and G. Kayakutlu, “Optimisation studies on tri-generation: A review,” Int. J. Energy Res., vol. 39, no. 10, pp. 1311-1334, 2015.

[11] D. Haeseldonckx, L. Peeters, L. Helsen, and W. D'haeseleer, "The impact of thermal storage on the operational behaviour of residential CHP facilities and the overall $\mathrm{CO}_{2}$ emissions," Renew. Sustain. Energy Rev., vol. 11, no. 6, pp. 1227-1243, Aug. 2007.

[12] T. Capuder and P. Mancarella, "Techno-economic and environmental modelling and optimization of flexible distributed multi-generation options," Energy, vol. 71, pp. 516-533, 2014.

[13] M. Bianchi, A. De Pascale, and F. Melino, "Performance analysis of an integrated CHP system with thermal and Electric Energy Storage for residential application,” Appl. Energy, vol. 112, pp. 928-938, 2013.

[14] D. Buoro, M. Casisi, A. De Nardi, P. Pinamonti, and M. Reini, "Multicriteria optimization of a distributed energy supply system for an industrial area," Energy, vol. 58, pp. 128-137, Sep. 2013.

[15] M. Rivarolo, A. Greco, and A. F. Massardo, "Thermo-economic optimization of the impact of renewable generators on poly-generation smart-grids including hot thermal storage," Energy Convers. Manag., vol. 65, pp. 75-83, 2013.

[16] A. Arteconi, N. J. Hewitt, and F. Polonara, "State of the art of thermal storage for demand-side management," Appl. Energy, vol. 93, pp. 371-389, May 2012.

[17] G. Li and X. Zheng, "Thermal energy storage system integration forms for a sustainable future," Renew. Sustain. Energy Rev., vol. 62, pp. 736-757, Sep. 2016.

[18] M. A. Lozano, A. Valero, and L. Serra, "Local optimization of energy systems," Am. Soc. Mech. Eng. Adv. Energy Syst. Div. AES, vol. 36, pp. 241-250, 1996.

[19] M. A. Lozano, M. Carvalho, and L. M. Serra, "Operational strategy and marginal costs in simple trigeneration systems,” Energy, vol. 34, no. 11, pp. 2001-2008, Nov. 2009.

[20] H. Li, Q. Sun, Q. Zhang, and F. Wallin, "A review of the pricing mechanisms for district heating systems,” Renew. Sustain. Energy Rev., vol. 42, pp. 56-65, 2015.

[21] V. Martinez-Sanchez, T. Hulgaard, C. Hindsgaul, C. Riber, B. Kamuk, and T. F. Astrup, 
"Estimation of marginal costs at existing waste treatment facilities," Waste Manag., vol. 50, pp. 364-375, Apr. 2016.

[22] C.-W. Hui, "Determining marginal values of intermediate materials and utilities using a site model," Comput. Chem. Eng., vol. 24, no. 2-7, pp. 1023-1029, Jul. 2000.

[23] P. Varbanov, S. Perry, Y. Makwana, X. X. Zhu, and R. Smith, "Top-level Analysis of Site Utility Systems,” Chem. Eng. Res. Des., vol. 82, no. June, pp. 784-795, 2004.

[24] J. Sjödin and D. Henning, "Calculating the marginal costs of a district-heating utility," Appl. Energy, vol. 78, no. 1, pp. 1-18, May 2004.

[25] A. M. Quelhas, E. Gil, and J. D. McCalley, "Nodal prices in an integrated energy system," Int. J. Crit. Infrastructures, vol. 2, no. 1, pp. 50-69, 2006.

[26] L. Schrage, “Optimization modeling with LINGO,” Lindo Systems, 1999.

[27] R. A. Gaggioli, "Second Law Analysis for Process and Energy Engineering," in Efficiency and Costing. ACS Symposium Series, vol. 235, 1983, pp. 3-50.

[28] M. A. Lozano and A. Valero, “Theory of the exergetic cost,” Energy, vol. 18, no. 9, pp. 939-960, Sep. 1993.

[29] M. A. Lozano, M. Carvalho, J. C. Ramos, and L. M. Serra, "Thermoeconomic analysis of simple trigeneration systems," Int. J. Thermodyn., vol. 12, no. 3, pp. 147-153, 2009.

[30] A. P. Rossiter and S. M. Ranade, "Marginal costs set the scene for profitable operation and investment in pinch retrofits," in Understanding Process Integration II - IChemE Symposium Series No. 109, 1988, pp. 283-301. 